\title{
Boston Bowel Preparation Segment Score 2
}

National Cancer Institute

\section{Source}

National Cancer Institute. Boston Bowel Preparation Segment Score 2. NCI Thesaurus.

Code C138209.

Minor amount of residual staining, small fragments of stool and/or opaque liquid, but mucosa of colon segment seen well. 